\title{
A lipoic acid-gamma linolenic acid conjugate is effective against multiple indices of experimental diabetic neuropathy
}

\author{
L. Hounsom ${ }^{1}$, D. F. Horrobin ${ }^{2}$, H. Tritschler ${ }^{3}$, R. Corder $^{4}$, D. R. Tomlinson ${ }^{1}$ \\ ${ }^{1}$ Department of Pharmacology, Queen Mary and Westfield College, London UK \\ ${ }^{2}$ Scotia Pharmaceuticals Ltd., Research \& Development Centre, Carlisle, UK \\ ${ }^{3}$ ASTA Medica AG, Frankfurt am Main, Germany \\ ${ }^{4}$ William Harvey Research Institute, London, UK
}

\begin{abstract}
Summary Untreated streptozotocin-diabetic (7 weeks duration) rats showed reductions (all $p<0.01$; percentages in brackets) in motor and sensory nerve conduction velocity (MNCV; 14\%, SNCV; 17\%) and in sciatic nerve contents of nerve growth factor (NGF; $57 \%$ ), substance P (SP; 53\%) and neuropeptide Y (NPY; $39 \%$ ). Treatment with a $\gamma$-linolenic acid- $\alpha-$ lipoic acid conjugate (GLA-LA; $35 \mathrm{mg} \cdot$ day $^{-1} \cdot$ rat $^{-1}$ ) attenuated $(p<0.05)$ these reductions to $\mathrm{MNCV}$ (8\%), SNCV (5\%), NGF (19\%), SP (23\%), NPY $(20 \%)$, such that the values in GLA-LA-treated diabetic rats did not differ significantly from those of control non-diabetic animals. Treatment with alpha-
\end{abstract}

lipoic acid alone at $100 \mathrm{mg} / \mathrm{kg}$ i.p. was without effect on these variables except for NGF $(33 \%$ reduction, $p<0.05)$ and treatment with the antioxidant, butylated hydroxytoluene ( $1.5 \%$ dietary supplement) did not affect any deficits. These data show that GLALA is effective in improving both electrophysiological and neurochemical correlates of experimental diabetic neuropathy. [Diabetologia (1998) 41: 839-843]

Keywords Alpha-lipoic acid, gamma-linolenic acid, nerve conduction, nerve growth factor, neuropeptide $\mathrm{Y}$, rat, substance $\mathrm{P}$.
Recent attempts to rationalise the aetiology of diabetic neuropathy have focused on two stages of pathogenesis. First, identification of the biochemical deficits that follow directly from hyperglycaemia, with the polyol pathway, protein glycation and free radical attack $[1,2]$. Second, attempts to identify the progenitors of dysfunction within the nerve itself. Here there has been a vigorous debate about the exis-

Received: 9th February 1998 and in revised from: 20th March 1998

Corresponding author: Professor D. R. Tomlinson, Department of Pharmacology, Queen Mary and Westfield College, Mile End Road, London E1 4NS, UK

Abbreviations: MNCV, Motor nerve conduction velocity; SNCV, sensory nerve conduction velocity; NPY, neuropeptide Y; NPY-LI, neuropeptide Y like-immunoreactivity; SP, substance P; SP-LI, substance P like-immunoreactivity; NGF, nerve growth factor; BHT, butylated hydroxytoluene; GLALA, gamma linolenic acid-lipoic acid; EFAs, essential fatty acids; NT-3, neurotrophin-3; STZ, Streptozotocin; BSA, bovine serum albumin. tence and importance of reduced nerve blood flow and consequent ischaemic damage [3-5]. Proponents of this mechanism suggest a chain of consequences comprising hyperglycaemia, exaggerated polyol pathway flux, impaired endoneurial nitric oxide production, reduced nerve blood flow, endoneurial hypoxia and impaired nerve conduction [6-8]. Related to this is the proposition that defective metabolism of essential fatty acids (EFAs) resulting in reduced levels of gamma-linolenic acid and subsequently, arachidonic acid also has a large part to play in the pathogenesis of diabetic neuropathy [9]. Others have argued the importance of impaired neurotrophic support from nerve growth factor (NGF) and neurotrophin 3 (NT-3) [10-13], but there is no rationale to suggest that these different mechanisms need be mutually exclusive. It is clear, however, that although treatment of rats with NGF or NT-3 prevents some of the deficits characteristic of experimental neuropathy $[10,12]$, these agents do not influence reduced nerve blood flow or motor conduction velocity [14]. Similarly, other agents, such as aldose reductase inhibitors or 
evening primrose oil offer only partial protection against experimental neuropathy, preventing blood flow and conduction deficits without affecting neurochemical defects derived from impaired neurotrophism $[15,16]$. More recently, the antioxidant $\alpha$-lipoic acid (thioctic acid) has been found to protect against a broader range of defects in diabetic rats [17-19], including both those related to nerve blood flow and those related to neurotrophins. The present study examined the effects of a novel conjugate of $\alpha$-lipoic acid and a triglyceride containing $\gamma$-linolenic acid (an active principle of evening primrose oil). This conjugate was compared with native $\alpha$-lipoic acid and another antioxidant, butylated hydroxytoluene (BHT). Measurements were designed to reflect both classes of defect referred to above, with motor and sensory conduction velocities indicating the polyolnerve blood flow axis, and NGF and neuropeptides as markers of neurotrophic support.

\section{Materials and methods}

Animals and experimental organisation. Male Wistar rats (range, 300-344 g) were randomly assigned to five groups. Four of these were made diabetic by a single i.p. injection of $50 \mathrm{mg} / \mathrm{kg}$ streptozotocin (STZ; Sigma, Poole, Dorset, UK) freshly dissolved in $\mathrm{NaCl} 154 \mathrm{mmol} / \mathrm{l}$ after fasting overnight. Blood glucose was measured $72 \mathrm{~h}$ later in tail vein blood by reflectance photometry ('Reflotest', Boehringer Mannheim, Mannheim, Germany) and animals with a resting blood glucose of less than $15 \mathrm{mmol} / \mathrm{l}$ were rejected from the study. Treatment was begun on the same day as hyperglycaemia (a resting blood glucose of $>15 \mathrm{mmol} / \mathrm{l}$ ) was confirmed with diabetic animals receiving $100 \mathrm{mg} / \mathrm{kg} \alpha$-lipoic acid (Asta Medica, Frankfurt am Main, Germany) i.p. five times a week, or butylated hydroxytoluene $1.5 \%$ dietary supplementation or $\gamma$-linolenic acid- $\alpha$-lipoic acid conjugate (GLA-LA; Scotia Pharmaceuticals, Carlisle, UK) via dietary supplementation at a dose of $50 \mathrm{mg}$ per $100 \mathrm{~g}$ of food, giving a daily consumption of approximately $35 \mathrm{mg}$. The last dose of either treatment was given $24 \mathrm{~h}$ before killing the rats. The remaining two groups, were one control (age matched) and one diabetic (untreated). The total duration of diabetes was 7 weeks.

Measurements of nerve conduction velocity. The procedure is described in full elsewhere [20]. Briefly, rats were anaesthetized with hypnorm $(0.6 \mathrm{ml} / \mathrm{kg}$ i.m. $)$ and diazepam $(2.5 \mathrm{mg} / \mathrm{kg}$ i.p.). Rectal temperature was monitored throughout the procedure and rats placed on a heating blanket to counteract the hypothermic effects of hypnorm anaesthesia. Nerve temperature was monitored using a thermocouple probe and maintained in the range of 36.5 to $37.5^{\circ} \mathrm{C}$ by radiant heat. The right sciatic nerve was stimulated first at the sciatic notch and then at the Achilles tendon. Stimulation comprised of $0.1 \mathrm{~ms}$ pulses of varying amplitude (1-4 V) were delivered via fine percutaneous needle electrodes using a Neurolog stimulus isolator (Digitimer Reasearch Instrumentation, Welwyn Garden City, UK). Consequent to each stimulation M-waves and h-reflexes were recorded using fine needle electrodes from the second interosseus muscle via a MacLab bridge amp and a digital storage type oscilloscope (Gould, Cambridge, UK) before being transferred to a MacLab/4 e (AD Instruments, Castle Hill,
New South Wales, Australia). Initially the h-reflex was recorded before subsequently increasing stimulation amplitude to generate M-waves. The reliability of the h-reflex was validated by its disappearance on generation of a maximal M-wave. The temporal separation of the peaks of $\mathrm{M}$-waves and h-reflexes were calculated using Chart v3.5 on an Apple Macintosh computer and the means of at least six measurements each of $\mathrm{M}$ waves and h-reflexes were taken. Nerve length from sciatic notch to Achilles tendon was measured at death and used to calculate motor nerve conduction velocity (MNCV) and sensory nerve conduction velocity (SNCV) in $\mathrm{m} / \mathrm{s}$.

Peptide and NGF measurements. Rats were exsanguinated after MNCV/SNCV measurements and sciatic nerves were removed for substance P (SP), NGF and neuropeptide Y (NPY) like immunoreactivity (LI). Sciatic nerve $(1 \mathrm{~cm})$ samples were boiled for $15 \mathrm{~min}$ in $0.8 \mathrm{ml}$ of $2 \mathrm{~mol} / \mathrm{l}$ acetic acid containing $10 \mathrm{mmol} / \mathrm{l}$ hydrochloric acid, $1 \mathrm{mmol} / \mathrm{l}$ EDTA and $1 \mathrm{mmol} / \mathrm{l} \mathrm{di}-$ thiothreitol. After boiling, samples were homogenised (Polytron, Kinematica, Lucerne, Switzerland) and centrifuged. Nerve samples were centrifuged at $11000 \times g$ for $5 \mathrm{~min}$. Supernatants were freeze dried overnight and lyophilates stored at $-70^{\circ} \mathrm{C}$ until assay. SP-LI in the sciatic nerve was determined by RIA using commercially available rabbit antisera (Amersham, Little Chalfont, UK) as published previously [21]. Neuropeptide Y like-immunoreactivity (NPY-LI) was determined by RIA from the same aliquot as that used for substance $\mathrm{P}$ like-immunoreactivity (SP-LI) measurements, using a secondary antibody precipitation method. Tissue lyophilates were reconstituted in $50 \mathrm{mmol} / \mathrm{l}$ phosphate buffer containing $0.5 \%$ bovine serum albumin (BSA) and $0.01 \%$ Triton X-100. We preincubated $100 \mu \mathrm{l}$ of samples (in duplicate) and standards (3.9-1000 fmol) overnight at $4{ }^{\circ} \mathrm{C}$ with $100 \mu \mathrm{l}$ 4RG2 (polyclonal rabbit anti-porcine NPY antibody; [22]; 1:480000 final concentration) and added $100 \mu \mathrm{l}$ of ${ }^{125}$ I-NPY labelled with Bolton Hunter reagent (Amersham, UK), total counts of approximately $10000 \mathrm{cpm}$, the next day. Samples were left to equilibrate at $4{ }^{\circ} \mathrm{C}$ for another $24 \mathrm{~h}$. Separation was achieved by the addition of $100 \mu \mathrm{l}$ of normal rabbit serum (1:80), $100 \mu \mathrm{l}$ sheep anti-rabbit secondary antibody (raised against the Fc fragment; IGi Ltd, Gateshead, UK; 1:16). Following a $3 \mathrm{~h}$ equilibration at $4{ }^{\circ} \mathrm{C}$ samples were centrifuged at $3000 \mathrm{rpm}$ for $30 \mathrm{~min}$ after the addition of $500 \mu \mathrm{l}$ buffer. Supernatants were discarded and pellets counted in a gamma counter. NGF levels were determined by ELISA using a kit (Boehringer Mannheim, Germany) as previously described [23].

Statistical analysis. Data are expressed as the arithmetic mean \pm 1 SD. One way analysis of variance (ANOVA) was performed, followed by Duncan's multiple range tests to correct for multiple comparisons. $P$ less than 0.05 was considered to be significant.

\section{Results}

The weight loss and glycaemia present in the diabetic rats are shown in Table 1 . None of the treatments affected the severity of diabetes as judged by these indices. Neurological data are also presented in Table 1. Untreated diabetic animals showed both conduction velocity deficits and reduced levels of NGF, neuropeptide Y (NPY) and SP in their sciatic nerves. Treatment with BHT was without effect on any of these variables. Treatment with $\alpha$-lipoic acid signifi- 
Table 1. Experimental data from all measurements

\begin{tabular}{llllllll}
\hline Group & $\begin{array}{l}\text { Final weight } \\
(\mathrm{g})\end{array}$ & $\begin{array}{l}\text { Blood glucose } \\
(\mathrm{mmol} / \mathrm{l})\end{array}$ & $\begin{array}{l}\text { NPY } \\
(\mathrm{fmol} / \mathrm{cm} \text { nerve })\end{array}$ & $\begin{array}{l}\text { SP } \\
(\mathrm{pg} / \mathrm{cm} \text { nerve })\end{array}$ & $\begin{array}{l}\text { NGF } \\
(\mathrm{pg} / \mathrm{cm} \text { nerve })\end{array}$ & $\begin{array}{l}\text { MNCV } \\
(\mathrm{m} / \mathrm{s})\end{array}$ & $\begin{array}{l}\text { SNCV } \\
(\mathrm{m} / \mathrm{s})\end{array}$ \\
\hline Control & $496 \pm 33(11)$ & $5.6 \pm 0.7$ & $117.7 \pm 24.7(11)$ & $81.9 \pm 25.0(10)$ & $73.7 \pm 26.3(9)$ & $49.3 \pm 6.8(11)$ & $51.5 \pm 7.4(10)$ \\
Diabetic & $289 \pm 29(10)$ & $21.7 \pm 2.5$ & $71.3 \pm 16.8(10)^{\mathrm{a}}$ & $38.4 \pm 15.4(8)^{\mathrm{a}}$ & $31.6 \pm 6.3(5)^{\mathrm{a}}$ & $42.5 \pm 3.1(10)^{\mathrm{a}}$ & $42.9 \pm 7.7(10)^{\mathrm{a}}$ \\
$\begin{array}{l}\text { Diabetic } \\
\text { BHT }\end{array}$ & $291 \pm 29(10)$ & $23.1 \pm 2.8$ & $77.2 \pm 11.1(9)^{\mathrm{a}}$ & $45.6 \pm 16.8(10)^{\mathrm{a}}$ & $40.1 \pm 18.5(5)^{\mathrm{b}}$ & $40.7 \pm 1.6(10)^{\mathrm{a}}$ & $45.0 \pm 4.7(9)^{\mathrm{a}}$ \\
$\begin{array}{l}\text { Diabetic } \\
\text { LA }\end{array}$ & $309 \pm 19(10)$ & $24.0 \pm 2.5$ & $86.9 \pm 27.3(9)^{\mathrm{a}}$ & $44.6 \pm 18.7(8)^{\mathrm{a}}$ & $49.2 \pm 24.7(8)$ & $41.0 \pm 7.0(10)^{\mathrm{a}}$ & $44.3 \pm 6.7(9)^{\mathrm{a}}$ \\
$\begin{array}{l}\text { Diabetic } \\
\text { GLA-LA }\end{array}$ & $332 \pm 19(10)$ & $20.7 \pm 3.0$ & $92.4 \pm 13.7(10)^{\mathrm{ac}}$ & $63.0 \pm 20.2(10)^{\mathrm{bc}}$ & $59.6 \pm 29.1(7)$ & $45.1 \pm 3.9(10)$ & $48.6 \pm 4.2(10)$
\end{tabular}

Data are mean $\pm 1 \mathrm{SD}$; animal numbers in brackets (numbers for blood glucose were the same as for body weight). Statistical comparisons were made by one-way ANOVA with Duncan's

cantly increased the NGF content of sciatic nerve and produced small arithmetic increases in both SP and NPY, which did not attain significance. There was no effect on either nerve conduction velocity. Treatment with the gamma linolenic acid-lipoic acid (GLA-LA) conjugate increased sciatic nerve levels of both SP and NPY, which were higher than those measured in nerves from untreated diabetic rats $(p<0.05)$, although they remained lower than those of controls $(p<0.05$ and 0.01 , respectively). The conjugate also increased NGF levels and both MNCV and SNCV so that these values were not different from those of control rats. The potential dependence of the neuropeptide changes on NGF levels was examined by regression analyses and the scatterplots are shown in Figure 1. For the dependence of SP on NGF $r^{2}$ was

Fig. 1. Scatterplots showing the associations between sciatic nerve neuropeptides (substance $\mathrm{P}$ (SP), left-hand plot, neuropeptide Y (NPY), right-hand plot) and nerve growth factor (NGF). SP and NPY were measured in the same extracts made from one segment of nerve, NGF was measured in the adjacent segment. There was an association between SP and NGF $\left(r^{2}=0.257\right)$, but not between NPY and NGF $\left(r^{2}=0.145\right)$ and the intercept for the latter was clearly not zero on the NPY axis multiple range tests where $F<0.05$. Levels were ${ }^{\mathrm{a}}=p<0.01 \mathrm{vs}$ controls, ${ }^{\mathrm{b}}=p<0.05$ vs controls, ${ }^{\mathrm{c}}=p<0.05$ vs diabetic

$0.257(p<0.005)$, but the levels of NPY were less closely related to those of NGF, where $r^{2}$ was 0.145 and the regression was barely significant $(p<0.05)$.

\section{Discussion}

The changes seen in untreated diabetic rats have all been reported before $[15,19,24]$; indeed the conduction deficits are classical. The reduced levels of NGF and SP correlate reasonably well in this, as in other studies, and the dependence of the latter on the former is well established. Treatment of normal or diabetic rats with NGF raises SP in the sciatic nerve [25, $26]$ and it is established that the promoter of the gene coding for the precursor of SP (preprotachykinin A) has a response element sensitive to NGF [27]. Thus the deficit in sciatic nerve SP in diabetic rats is secondary to reduced axonal transport [28] of NGF and the latter relates both to reduced production of NGF by the target tissues [28,29] and to reduced production of receptors by the neurone [30].

The explanation of NPY deficit is not so clear. NPY in the sciatic nerve may derive from mixed fibre populations - some must be in sympathetic postganglionic fibres $[31,32]$ - but there could also be some in somatic sensory fibres. The expression in somatic

Sciatic nerve NGF versus NPY

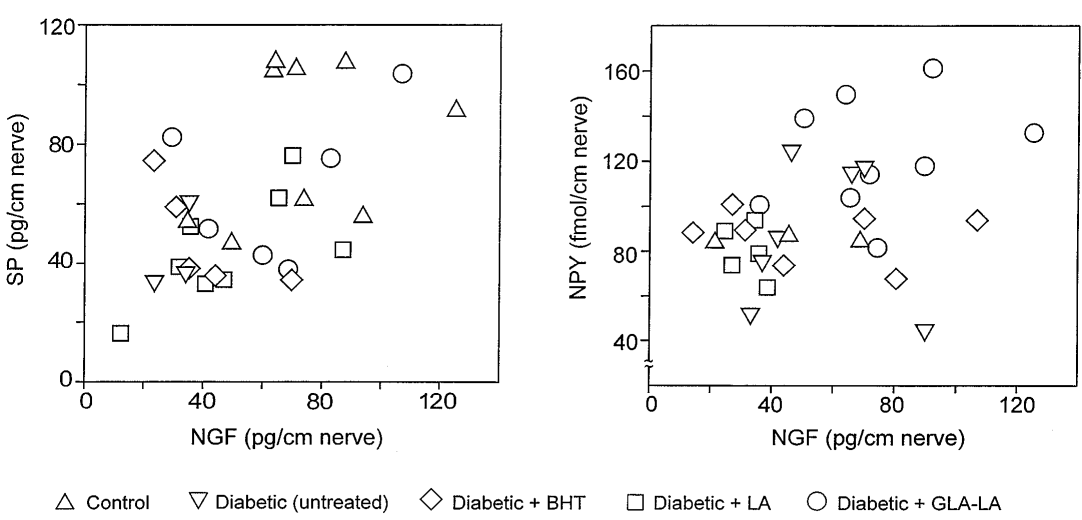

$\triangle$ Control $\quad \nabla$ Diabetic (untreated) $\diamond$ Diabetic + BHT $\quad \square$ Diabetic + LA $O$ Diabetic + GLA-LA 
afferents is low, however, unless they are damaged, when it increases [33]; after axotomy, this increased expression may be reduced by either NT-3 or NGF $[34,35]$. Expression of NPY by the sympathetic phenotype is clearly stimulated by NGF [36] and NGFresponsive elements have been identified on the NPY promoter [37]. Thus, our findings could be explained by the proposition that the NPY deficit in sciatic nerves of diabetic rats is also derived from reduced NGF neurotrophic support. Our previous study, however, showed that treatment of diabetic rats with NGF, returned SP in sciatic nerve to normal but did not affect the NPY deficit [19]. Thus, there may be control of NPY expression in these fibres by another neurotrophin with NGF response elements becoming functional only when other influences are removed. This could explain the NGF effects on NPY in vitro $[36,38]$ and increases in NPY after axotomy in vivo $[33,39]$. Thus, the evolution of the decrease in NPY expression in our diabetic rats cannot be explained as yet, though the deficit clearly responds to treatment with the GLA-LA conjugate and, in our previous study, also responded to $\alpha$-lipoic acid [19]. We suggest an examination of the effects of this conjugate on other neurotrophic deficits in nerve of diabetic rats would pay dividends. Of particular note is the range of deficits which was attenuated by the conjugate in this study applying to both electrophysiological and neurochemical deficits in the nerves of diabetic rats.

The effect of the GLA-LA conjugate is also remarkable when related to the current effects of $\alpha$-lipoic acid and previously reported effects of evening primrose oil. Approximate calculations suggest that the dose of GLA-LA used here, could deliver about $14 \mathrm{mg} \cdot \mathrm{kg}^{-1} \cdot \mathrm{day}^{-1} \alpha$-lipoic acid and $18 \mathrm{mg} \cdot \mathrm{kg}^{-1}$. day $^{-1} \gamma$-linolenic acid. $\alpha$-Lipoic acid must be given at least $50 \mathrm{mg} \cdot \mathrm{kg}^{-1} \cdot \mathrm{day}^{-1}$ to influence nerve conduction [18] and in the present and previous [19] studies had little effect on sciatic nerve NGF levels at $100 \mathrm{mg} \cdot \mathrm{kg}^{-1} \cdot$ day $^{-1}$. Assuming an approximate content of $10 \% \gamma$-linolenic acid in evening primrose oil [40], a daily consumption of about $180 \mathrm{mg}$ oil would be required to match the current dose of conjugate. A previous study demonstrated no effect of evening primrose oil at about $3.5 \mathrm{~g} \cdot \mathrm{rat}^{-1} \cdot$ day $^{-1}$ (equivalent to about $10 \mathrm{~g} \cdot \mathrm{kg}^{-1} \cdot \mathrm{day}^{-1}$ ) on the deficit in sciatic nerve SP in diabetic rats [16]. It is, therefore, clear that the properties of the conjugate are significantly greater than those of its constituent molecules and it may be that the conjugate maintains the antioxidant properties of $\alpha$-lipoic acid $[17,41]$ in a particularly influential part of the cell. We suspected that a membrane localisation might be important and that was why BHT, a lipid soluble antioxidant, was included in this study; but it showed no efficacy indicating that simple membrane sequestration of $\alpha$-lipoic acid does not provide an explanation for the efficacy of the conjugate. Furthermore, although NGF treatment of diabetic rats does not affect nerve conduction deficits, the conjugate had multiple protective effects on different fibre groups, i. e. increasing nerve NGF, stimulating NPY expression by a different mechanism and boosting deficient conduction velocities. Clearly, this molecule shows clinical potential.

Acknowledgements. This study was supported by donations from Scotia Pharmaceuticals and Asta Medica. We are grateful to Geert Jan Biessels for advice about the measurement of the h-reflex.

\section{References}

1. Biessels GJ, Van Dam PS (1997) Diabetic neuropathy: pathogenesis and current treatment perspectives. Neurosci Res Commun 20: 1-10

2. Yagihashi S (1996) Pathology and pathogenetic mechanisms of diabetic neuropathy. Diabetes Metab Rev 11: 193-225

3. Dyck PJ, Giannini C (1996) Pathologic alterations in the diabetic neuropathies of humans: A review. J Neuropathol Exp Neurol 55: 1181-1193

4. Tesfaye S, Malik R, Ward JD (1994) Vascular factors in diabetic neuropathy. Diabetologia 37: 847-854

5. Williamson JR, Chang K, Frangos M et al. (1993) Hyperglycemic pseudohypoxia and diabetic complications. Diabetes 42: 801-813

6. Cameron NE, Cotter MA, Basso M, Hohman TC (1997) Comparison of the effects of inhibitors of aldose reductase and sorbitol dehydrogenase on neurovascular function, nerve conduction and tissue polyol pathway metabolites in streptozotocin-diabetic rats. Diabetologia 40: 271-281

7. Sasaki H, Schmelzer JD, Zollman PJ, Low PA (1997) Neuropathology and blood flow of nerve, spinal roots and dorsal root ganglia in longstanding diabetic rats. Acta Neuropathol (Berl) 93: 118-128

8. Kihara M, Low PA (1995) Impaired vasoreactivity to nitric oxide in experimental diabetic neuropathy. Exp Neurol 132: $180-185$

9. Horrobin DF (1988) The roles of essential fatty acids in the development of diabetic neuropathy and other complications of diabetes mellitus. Prostaglandins Leukotrienes Essen Fatty Acids 31: 181-197

10. Tomlinson DR, Fernyhough P, Diemel LT (1997) Role of neurotrophins in diabetic neuropathy and treatment with nerve growth factors. Diabetes 46:S43-S49

11. Dyck PJ (1996) Nerve growth factor and diabetic neuropathy. Lancet 348: 1044-1045

12. Tomlinson DR, Fernyhough P, Diemel LT (1996) Neurotrophins and peripheral neuropathy. Philos Trans R Soc Lond B Biol Sci 351: 455-462

13. Thomas PK (1994) Growth factors and diabetic neuropathy. Diabet Med 11: 732-739

14. Maeda K, Fernyhough P, Tomlinson DR (1997) Effects of treatment of diabetic rats with human recombinant nerve growth factor on sciatic nerve conduction, Doppler flux and substance P levels. Diabet Nutr Metab 10: 3-8

15. Robinson JP, Willars GB, Tomlinson DR, Keen P (1987) Axonal transport and tissue contents of substance $\mathrm{P}$ in rats with long-term streptozotocin-diabetes. Effects of the aldose reductase inhibitor 'statil'. Brain Res 426: 339-348 
16. Tomlinson DR, Robinson JP, Compton AM, Keen P (1989) Essential fatty acid treatment-effects on nerve conduction, polyol pathway and axonal transport in streptozotocin diabetic rats. Diabetologia 32: 655-659

17. Packer L (1994) Antioxidant properties of lipoic acid and its therapeutic effects in prevention of diabetes complications and cataracts. Ann NY Acad Sci 738: 257-264

18. Nagamatsu M, Nickander KK, Schmelzer JD et al. (1995) Lipoic acid improves nerve blood flow, reduces oxidative stress, and improves distal nerve conduction in experimental diabetic neuropathy. Diabetes Care 18: 1160-1167

19. Garrett NE, Malcangio M, Dewhurst M, Tomlinson DR (1997) $\alpha$-Lipoic acid corrects neuropeptide deficits in diabetic rats via induction of trophic support. Neurosci Lett 222: 191-194

20. Sharma AK, Thomas PK (1974) Peripheral nerve structure and function in experimental diabetes. J Neurol Sci 23: $1-15$

21. Brewster WJ, Diemel LT, Leach RM, Tomlinson DR (1994) Reduced sciatic nerve substance P and calcitonin gene-related peptide in rats with short-term diabetes or central hypoxaemia coexist with normal messenger RNA levels in the lumbar dorsal root ganglia. Neuroscience 58: 323-330

22. Corder R, Lowry PJ (1985) An immunoradiometric assay for the measurement of neuropeptide $\mathrm{Y}$ in plasma. Peptides 6: 1195-1200

23. Fernyhough P, Diemel LT, Brewster WJ, Tomlinson DR (1994) Deficits in sciatic nerve neuropeptide content coincide with a reduction in target tissue nerve growth factor mRNA in streptozotocin-diabetic rats; effects of insulin treatment. Neuroscience 62: 337-344

24. Hellweg R, Hartung H-D (1990) Endogenous levels of nerve growth factor (NGF) are altered in experimental diabetes mellitus: a possible role for NGF in the pathogenesis of diabetic neuropathy. J Neurosci Res 26: 258-267

25. Apfel SC, Arezzo JC, Brownlee M, Federoff H, Kessler JA (1994) Nerve growth factor administration protects against experimental diabetic sensory neuropathy. Brain Res 634: 7-12

26. Diemel LT, Brewster WJ, Fernyhough P, Tomlinson DR (1994) Expression of neuropeptides in experimental diabetes; effects of treatment with nerve growth factor or brainderived neurotrophic factor. Mol Brain Res 21: 171-175

27. Gilchrist CA, Morrison CF, Chapman KE, Harmar AJ (1991) Identification of nerve growth factor-responsive sequences within the 5 ' region of the bovine preprotachykinin gene. DNA Cell Biol 10: 743-749

28. Fernyhough P, Diemel LT, Hardy J, Brewster WJ, Mohiuddin L, Tomlinson DR (1995) Human recombinant nerve growth factor replaces deficient neurotrophic support in the diabetic rat. Eur J Neurosci 7: 1107-1110
29. Fernyhough P, Diemel LT, Brewster WJ, Tomlinson DR (1995) Altered neurotrophin mRNA in peripheral nerve and skeletal muscle of experimentally diabetic rats. J Neurochem 64: 1231-1237

30. Delcroix J, Tomlinson DR, Fernyhough P (1997) Diabetes and axotomy-induced deficits in retrograde axonal transport of nerve growth factor correlate with decreased levels of $\mathrm{p}^{75 \mathrm{LNTR}}$ protein in lumbar dorsal root ganglia. Mol Brain Res 51: 82-90

31. Lundberg JM, Terenius L, Hokfelt T et al. (1982) Neuropeptide Y (NPY)-like immunoreactivity in peripheral noradrenergic neurons and effects of NPY on sympathetic function. Acta Physiol Scand 116: 477-480

32. Tatemoto K, Carlquist M, Mutt V (1982) Neuropeptide Y a novel brain peptide with structural similarities to peptide YY and pancreatic polypeptide. Nature 296: 659-660

33. Wakisaka S, Kajander KC, Bennett GJ (1991) Increased neuropeptide Y (NPY)-like immunoreactivity in rat sensory neurons following peripheral axotomy. Neurosci Lett 124: 200-203

34. Ohara S, Tantuwaya V, DiStefano PS, Schmidt RE (1995) Exogenous NT-3 mitigates the transganglionic neuropeptide $\mathrm{Y}$ response to sciatic nerve injury. Brain Res 699: 143-148

35. Verge VMK, Richardson PM, Wiesenfeld-Hallin Z, Hökfelt T (1995) Differential influence of nerve growth factor on neuropeptide expression in vivo: a novel role in peptide suppression in adult sensory neurons. J Neurosci 15: 2081-2096

36. Allen JM, Tischler AS, Lee YC, Bloom SR (1984) Neuropeptide Y (NPY) in PC12 phaeochromocytoma cultures: responses to dexamethasone and nerve growth factor. Neurosci Lett 46: 291-296

37. Higuchi H, Nakano K, Miki N (1992) Identification of NGF-response element in the rat neuropeptide $Y$ gene and induction of the binding proteins. Biochem Biophys Res Commun 189: 1553-1560

38. Balbi D, Allen JM (1994) Role of protein kinase C in mediating NGF effect on neuropeptide Y expression in PC12 cells. Brain Res Mol Brain Res 23: 310-316

39. Zhang X, Wiesenfeld-Hallin Z, Hökfelt T (1994) Effect of peripheral axotomy on expression of neuropeptide $\mathrm{Y}$ receptor mRNA in rat lumbar dorsal root ganglia. Eur J Neurosci 6: 43-57

40. Lockett MJ, Tomlinson DR (1992) The effects of dietary treatment with essential fatty acids on sciatic nerve conduction and activity of the $\mathrm{Na}^{+} / \mathrm{K}^{+}$pump in streptozotocin-diabetic rats. Br J Pharmacol 105: 355-360

41. Packer L, Witt EH, Tritschler HJ (1995) $\alpha$-Lipoic acid as a biological antioxidant. Free Radic Biol Med 19: 227-250 